\title{
KOMPOZYTY CEMENTOWE MODYFIKOWANE AKTYWOWANYM TERMICZNIE DODATKIEM RECYKLINGOWYM
}

\author{
Katarzyna Kalinowska-Wichrowska ${ }^{凶}$ \\ Wydział Budownictwa i Inżynierii Środowiska, Politechnika Białostocka, Białystok
}

\begin{abstract}
STRESZCZENIE
W artykule zaprezentowano wyniki badań własnych nad kompozytami cementowymi, których skład zmodyfikowano dodatkiem recyklingowym powstałym (obok kruszyw recyklingowych) w wyniku specjalnie opracowanego procesu recyklingu betonu objętego polskim patentem PAT.229887 (2018). Wykorzystanie tak przygotowanej zaprawy recyklingowej w charakterze dodatku typu II lub jedynie wypełniacza w kompozytach cementowych to trafna droga do zagospodarowania tego materiału i silny akcent w kierunku zrównoważonego budownictwa. Jak dowodzą wyniki badań, odpowiednio dobrane parametry procesu obróbki cieplno-mechanicznej pozwalają na aktywację właściwości pucolanowych tego materiału. Proponowana metoda recyklingu jest przykładem kompleksowego rozwiązania problemu, jakim jest całkowite przetworzenie gruzu betonowego w wartościowe produkty wtórne i ponowne włączenie ich do procesu produkcji budowlanej.
\end{abstract}

Słowa kluczowe: zaprawa recyklingowa, recykling betonu, zrównoważony rozwój, gospodarka odpadami

\section{WSTĘP}

Drobna frakcja z recyklingu betonu to głównie fragmenty rozdrobnionych kruszyw, piasek recyklingowy oraz stary zaczyn. W badaniach Il'iny i Mukhiny (2016) badano skład chemiczny zaprawy recyklingowej i stwierdzono, że zawiera ona uwodnione cząstki cementu oraz drobne kruszywo. Zawartość objętościowa zaprawy na kruszywach recyklingowych może wynosić 41\% (Abbas i in., 2008; Nam, An i Youn, 2016). W innych badaniach stwierdzono także, że w obrębie kruszywa recyklingowego (zaprawy) występuje nieprzehydratyzowany cement, wodorotlenek wapnia $(\mathrm{CH})$ i krzemian dwuwapniowy $\left(\mathrm{C}_{2} \mathrm{~S}\right)$ (Poon, Qiao i Chan, 2006; Chai, Monismith i Harvey, 2009) i są one zdolne do uwodnienia i tworzenia produktów rehydratacji (Shui, Xuan, Wan i Cao, 2008; Paige-Green, 2010). W związku z tym, jak podali Lotfi,
Eggimann, Wagner, Mróz i Deja (2015), w trakcie produkcji kompozytów cementowych z wykorzystaniem wtórnych zapraw można zmniejszyć zużycie cementu o 10\%. Zważywszy na znaczną ilość nieprzehydratyzowanego cementu znajdującego się w drobnej frakcji $\mathrm{z}$ recyklingu betonu, Bordy, Younsi, Aggoun i Fiorio (2017) analizowali właściwości kompozytów wykonanych z substytutem drobno zmielonego proszku wytworzonego ze starych, stwardniałych zaczynów cementowych. Zauważono, że w zaczynie było około 24\% aktywnego nieprzereagowanego klinkieru, który może na nowo ulec hydratacji. Niestety parametry wytrzymałościowe takich kompozytów uległy spadkowi. Shui i inni (2008) studiowali właściwości wiążące takiego materiału po jego prażeniu $\mathrm{w}$ temperaturze $800^{\circ} \mathrm{C}$, jednak ze względu na kalcynację węglanu wapnia i uwalnianie dwutlenku węgla nie uzyskano oczekiwanych rezultatów. Ponowne zastosowanie

${ }^{凶}$ k.kalinowska@pb.edu.pl 
drobnej frakcji recyklingowej w kompozytach cementowych jest chętnie podejmowanym tematem badań naukowców, a sam materiał wydaje się rokować jako wartościowy składnik takich kompozytów. Najbardziej istotną kwestią pozostaje jednak odpowiednie jego uzdatnienie w celu uzyskania poprawy parametrów kompozytów, np. wytrzymałościowych.

\section{MATERIAt I METODY}

\section{Charakterystyka surowców}

Do badań zastosowano cement, piasek i zaprawę recyklingową. Cement portlandzki: CEM I 42,5R odpowiadał wymogom normy PN-EN 197-1. Wykorzystany piasek spełnia normę CEN frakcji 0-2 mm i ma certyfikat zgodności z normą PN-EN 196-1:2006. Został on dostarczony (w workach o masie netto $1350 \pm 5 \mathrm{~g}$ ) z firmy KWARCMIX. Zaprawe recyklingową uzyskano $\mathrm{z}$ odsiania frakcji mniejszej od $0,25 \mathrm{~mm}$, pochodzacej z obróbki termiczno-mechanicznej gruzu betonowego (parametry obróbki według planu eksperymentu). Gruz betonowy pochodził z krawężników drogowych po trzyletniej eksploatacji. Beton pierwotny (klasa wytrzymałości $\mathrm{C} 35 / 35$ ) zawierał $360 \mathrm{~kg}$ cementu na $1 \mathrm{~m}^{3}$ mieszanki betonowej, przy zachowaniu proporcji wody do cementu (w/c) na poziomie 0,5 . W przyjętym eksperymencie $25 \%$ masy potrzebnego cementu zastąpiono zaprawą recyklingową.

\section{Metodyka badań}

Badania wytrzymałości na zginanie przeprowadzono na sześciu próbkach losowo wybranych z każdej serii liczącej 18 beleczek o wymiarach $4 \times 4 \times 16 \mathrm{~cm}$, a badania wytrzymałości na ściskanie wykonano na 12 przełomach tych próbek $(4 \times 4 \times 8 \mathrm{~cm})$ uzyskanych po wykonaniu badania wytrzymałości na zginanie. Badania wykonano z użyciem maszyny wytrzymałościowej zgodnie z normą PN-EN 196-1:2006.

Badanie konsystencji zapraw wykonano metodą stolika rozpływowego według normy PN-EN 1015$-3: 2000 / \mathrm{A} 1: 2005$.

\section{Eksperyment badawczy}

Doświadczenie zakładało określenie najkorzystniejszej temperatury i czasu prażenia zaprawy recyklingowej (pozyskanej z obróbki termiczno-mechanicznej gruzu betonowego) wykorzystanej jako zamiennik części cementu na wybrane właściwości kompozytów cementowych. W pierwszej kolejności gruz betonowy poddano obróbce termiczno-mechanicznej, która polegała na jego wyprażeniu w piecu termicznym, a następnie mechanicznemu odspajaniu zaprawy od kruszywa, która odbywała się w bębnie Los Angeles nastawionym na 500 obrotów. Jednorazowy wsad wynosił około $30 \mathrm{~kg}$. Parametry obróbki termicznej stały się czynnikami zmiennymi w zaplanowanym eksperymencie. Metoda i sposób przyjętej obróbki gruzu betonowego sa efektem wieloletnich badań zespołu badawczego z Politechniki Białostockiej i przedmiotem patentu PAT.229887 (2018).

Przedziały zmienności czynników wejściowych (ilościowych) przedstawiają się następująco:

- $X_{1}$ - temperatura prażenia gruzu betonowego (finalnie zaprawy) $-430-770^{\circ} \mathrm{C}$;

- $X_{2}$ - czas prażenia gruzu betonowego (finalnie zaprawy) - 31-90 min.

W przyjętym eksperymencie $25 \%$ masy potrzebnego cementu zastąpiono zaprawą recyklingową uzyskaną po przesianiu przez sito o średnicy oczek $0,25 \mathrm{~mm}$ gruzu betonowego poddanego opisanej wcześniej obróbce. Użycie zaprawy recyklingowej w tej ilości pozwala jednocześnie na kwalifikację materiału pod kątem dodatku pucolanowego według normy PN-EN 450-1:2012.

Przy wyborze planu eksperymentu uwzględniono konieczność uzyskania adekwatnych opisów matematycznych rozpatrywanych funkcji celu i możliwość skrócenia liczby prób. Eksperyment oparto na planie dwuczynnikowym polisekcyjno-rotalno-quasi-uniformalnym (PS/DS.-P: $\lambda(\tilde{\lambda}), i=2) \mathrm{z}$ dwukrotnym powtórzeniem doświadczenia $\mathrm{w}$ punkcie centralnym. Macierz planowania eksperymentu dla wielkości kodowanych i rzeczywistych przedstawiono w tabeli 1.

Próbki laboratoryjne zostały wykonane w 10 różnych seriach (seria 9 powtórzona). Wykonano także serię kontrolną (11) - bez dodatku zaprawy recyklingowej oraz serię 12 zawierającą dodatek zapraw recyklingowej niepoddawanej obróbce termicznej. Po 27 dniach dojrzewania w warunkach wodnych wykonano pomiary wytrzymałości na zginanie i nasiąkliwości na beleczkach o wymiarach $4 \times 4 \times 16 \mathrm{~cm}$ oraz wytrzymałości 
Kalinowska-Wichrowska, K. (2019). Kompozyty cementowe modyfikowane aktywowanym termicznie dodatkiem recyklingowym. Acta Sci. Pol. Architectura 18 (1), 39-45, DOI: 10.22630/ASPA.2019.18.1.5

Tabela 1. Macierz planowania eksperymentu dla naturalnych i kodowanych czynników wejściowych w postaci temperatury prażenia $\left(X_{1}\right)$ i czasu prażenia $\left(X_{2}\right)$ gruzu betonowego

Table 1. The experiment planning matrix for natural and coded input factors in the form of roasting temperature $\left(X_{1}\right)$ and roasting time $\left(X_{2}\right)$ of concrete debris

\begin{tabular}{ccccc}
\hline \multirow{2}{*}{$\begin{array}{c}\text { Seria } \\
\text { Series }\end{array}$} & \multicolumn{2}{c}{$\begin{array}{c}\text { Wielkości kodowane } \\
\text { Coded values }\end{array}$} & \multicolumn{2}{c}{$\begin{array}{c}\text { Wielkości rzeczywiste } \\
\text { Real values }\end{array}$} \\
\cline { 2 - 5 } & $x_{1}$ & $x_{2}$ & $\begin{array}{c}X_{1} \\
{\left[{ }^{\circ} \mathrm{C}\right]}\end{array}$ & $\begin{array}{c}X_{2} \\
{[\mathrm{~min}]}\end{array}$ \\
\hline 1 & -1 & -1 & 550 & 39 \\
2 & -1 & 1 & 550 & 81 \\
3 & 1 & -1 & 650 & 39 \\
4 & 1 & 1 & 650 & 81 \\
5 & $-1,414$ & 0 & 430 & 60 \\
6 & 1,414 & 0 & 770 & 60 \\
7 & 0 & $-1,414$ & 600 & 30 \\
8 & 0 & 1,414 & 600 & 90 \\
9 & 0 & 0 & 600 & 60 \\
10 & 0 & 0 & 600 & 60 \\
\hline
\end{tabular}

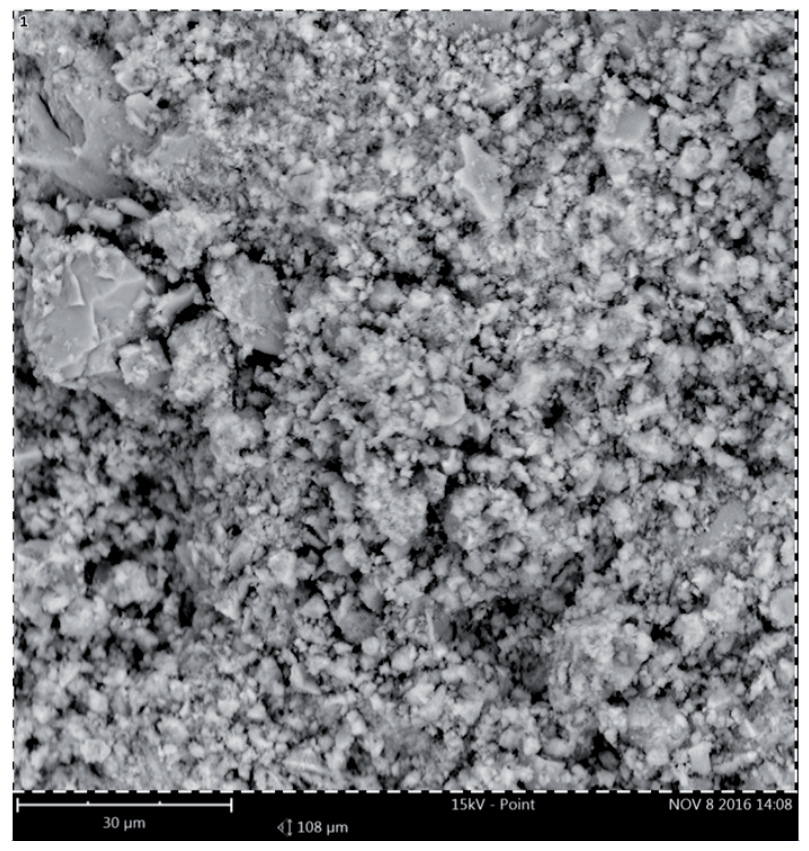

Rys. 1. Zdjęcie SEM zaprawy recyklingowej po obróbce termicznej $\mathrm{w} 770^{\circ} \mathrm{C}$

Fig. 1. The SEM photo of recycled mortar after calinated in $770^{\circ} \mathrm{C}$

temperaturze. Oprócz tego widoczne są prawdopodobnie resztki nieprzehydratyzowanego cementu.

Skład tlenkowy wykonany za pomocą techniki EDS jest następujący: wapń 66,82; krzem 16,23; glin 13,87; siarka 2,11 i magnez 0,97.

W tabeli 3 zestawiono wyniki pomiaru konsystencji wybranych serii zapraw z wykorzystaniem materiału recyklingowego.

Tabela 2. Receptury mieszanek kompozytów cementowych na jedną formę (trzy beleczki $4 \times 4 \times 16 \mathrm{~cm}$ )

Table 2. Mixtures of cement composites with one form (three bars $4 \times 4 \times 16 \mathrm{~cm}$ )

\begin{tabular}{|c|c|c|c|c|c|}
\hline $\begin{array}{l}\text { Seria } \\
\text { Series }\end{array}$ & $\begin{array}{c}\text { Proporcja w/c } \\
+ \text { zaprawa } \\
\mathrm{w} / \mathrm{c}+\text { mortar ratio } \\
\end{array}$ & $\begin{array}{l}\text { CEM I } \\
42,5 \mathrm{R} \\
{[\mathrm{g}]} \\
\end{array}$ & $\begin{array}{c}\text { Zaprawa recyklingowa } \\
\text { Recycling mortar } \\
{[\mathrm{g}]}\end{array}$ & $\begin{array}{l}\text { Woda } \\
\text { Water } \\
{\left[\mathrm{cm}^{3}\right]}\end{array}$ & $\begin{array}{c}\text { Piasek normowy } \\
\text { Standard sand } \\
{[\mathrm{g}]} \\
\end{array}$ \\
\hline $\begin{array}{l}\text { Serie podstawowe }(1-10) \\
\text { Basic series }(1-10)\end{array}$ & 0,5 & 337,5 & 112,5 & 225 & 1350 \\
\hline $\begin{array}{l}\text { Seria kontrolna (11) } \\
\text { Control (11) }\end{array}$ & 0,5 & 450 & 0 & 225 & 1350 \\
\hline $\begin{array}{l}\text { Seria dodatkowa (12), zaprawa } \\
\text { recyklingowa bez obróbki termicznej } \\
\text { Extra series (12), recycling mortar } \\
\text { without thermal treatment }\end{array}$ & 0,5 & 337,5 & 112,5 & 225 & 1350 \\
\hline
\end{tabular}


Kalinowska-Wichrowska, K. (2019). Kompozyty cementowe modyfikowane aktywowanym termicznie dodatkiem recyklingowym. Acta Sci. Pol. Architectura 18 (1), 39-45, DOI: 10.22630/ASPA.2019.18.1.5

Tabela 3. Zestawienie wyników konsystencji badanych kompozytów cementowych (świeżych zapraw)

Table 3. Comparison of the consistency results of the cementitious composites tested (fresh mortars)

\begin{tabular}{|c|c|}
\hline $\begin{array}{l}\text { Rodzaj kompozytu } \\
\text { Type of composite }\end{array}$ & $\begin{array}{c}\text { Miara konsystencji } \\
\text { Consistency mass } \\
{[\mathrm{cm}]}\end{array}$ \\
\hline $\begin{array}{l}\text { Zaprawa z dodatkiem zaprawy recyklingowej poddanej uprzedniemu prażeniu w } 430^{\circ} \mathrm{C} \\
\text { Standard mortar with addition recycling mortar calcinatied in } 430^{\circ} \mathrm{C}\end{array}$ & 15 \\
\hline $\begin{array}{l}\text { Zaprawa z dodatkiem zaprawy recyklingowej poddanej uprzedniemu prażeniu w } 650^{\circ} \mathrm{C} \\
\text { Standard mortar with addition recycling mortar calcinated in } 650^{\circ} \mathrm{C}\end{array}$ & 14 \\
\hline $\begin{array}{l}\text { Zaprawa } \mathrm{z} \text { dodatkiem zaprawy recyklingowej poddanej uprzedniemu prażeniu w } 770^{\circ} \mathrm{C} \\
\text { Standard mortar with addition recycling mortar calinated in } 770^{\circ} \mathrm{C}\end{array}$ & 13,5 \\
\hline $\begin{array}{l}\text { Zaprawa normowa } \\
\text { Standard mortar }\end{array}$ & 17 \\
\hline
\end{tabular}

${ }^{a}$ Średnia arytmetyczna obu średnic z dwóch pomiarów - Arithmetic average of both diameters from two measurements.

Zaprawa recyklingowa użyta do badań charakteryzowała się znaczną zawartości frakcji mniejszej od 0,063 mm (ok. 60\%), w której skład wchodzą zmielone: kamień cementowy, fragmenty kruszywa i nieprzehydratyzowany cement, co odpowiada za jej wzmożoną wodożądność. Pomimo tego przy wykonywaniu mieszanek kompozytów nie było konieczne zwiększenie ilości wody w recepturze w celu dokładnego wymieszania wszystkich składników.

\section{WYNIKI}

\section{Wytrzymałość na ściskanie i wskaźnik pucolanowości}

Na rysunku 2 przedstawiono zestawienie uzyskanych wyników wytrzymałości na ściskanie kompozytów cementowych z dodatkiem zaprawy recyklingowej.

Analizując wyniki przedstawione na rysunku 2, stwierdzono, że największe wartości wytrzymałości

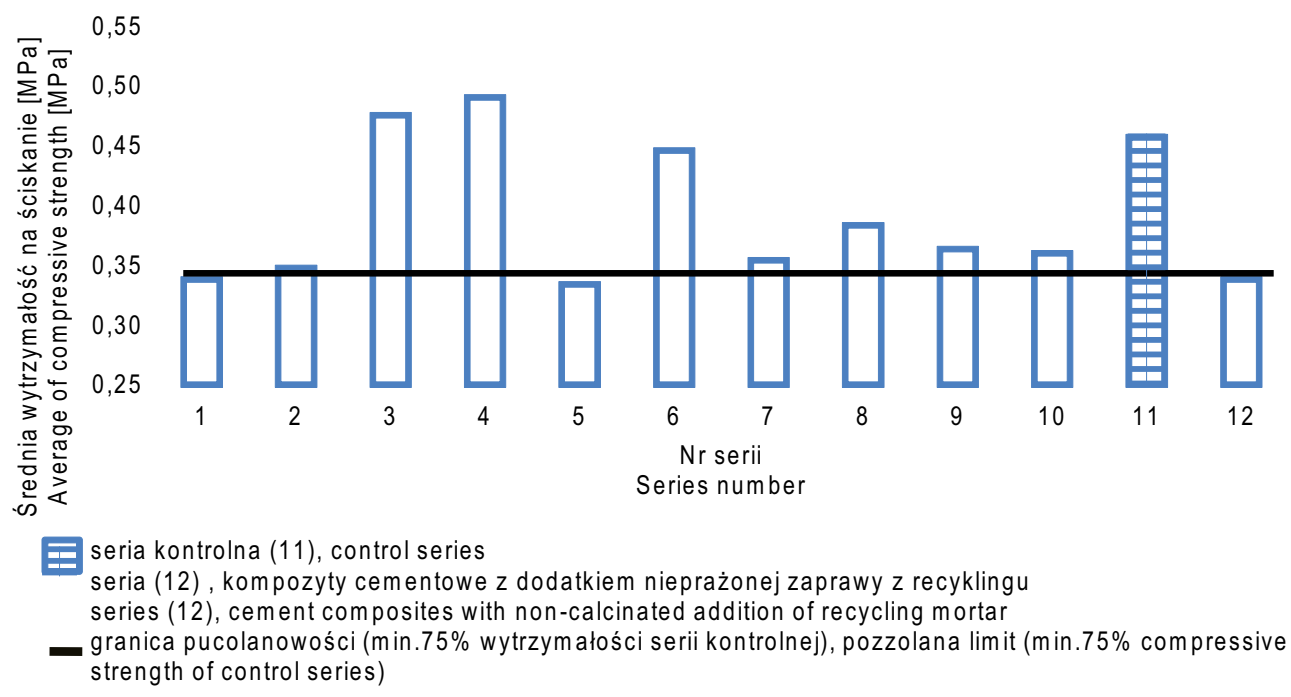

Rys. 2. Zestawienie wyników średniej wytrzymałości na ściskanie kompozytów cementowych z dodatkiem zaprawy recyklingowej

Fig. 2. Comparison of the results of medium compressive strength of cementitious composites with the addition of a recyclable mortar 
na ściskanie uzyskano dla serii 4, w której zastosowano temperaturę prażenia około $650^{\circ} \mathrm{C}$. Był to wzrost o około $7 \%$ w stosunku do wyników uzyskanych dla serii kontrolnej. W przypadku serii 12 wykonanej $\mathrm{z}$ dodatkiem zaprawy recyklingowej, która nie była poddawana obróbce termicznej, zanotowano spadek wytrzymałości w stosunku do serii kontrolnej (11) o około $26 \%$ i $31 \%$ w porównaniu do serii 4 - najkorzystniejszej pod względem uzyskanych parametrów wytrzymałości na ściskanie. Zauważyć także należy, że jedynie w przypadku serii, w których temperatura prażenia wynosiła ponad $600^{\circ} \mathrm{C}$, odnotowywano wystapienie właściwości pucolanowych dodatku zaprawy recyklingowej (wytrzymałość na ściskanie wynosiła przynajmniej $75 \%$ wytrzymałości na ściskanie serii kontrolnej), a najkorzystniejsze rezultaty świadczące o dużej aktywności pucolanowej materiału uzyskano $\mathrm{w}$ przypadku zastosowania temperatury prażenia $650^{\circ} \mathrm{C}$ (wskaźnik pucolanowości na poziomie 107\%).

\section{Wytrzymałość na zginanie}

Analizując wyniki przedstawione na rysunku 3, stwierdzono, że największe wyniki wytrzymałości na zginanie uzyskano dla serii 3 i 4 (prażenie $\mathrm{w} 650^{\circ} \mathrm{C}$ ) i były one zbliżone do tych uzyskiwanych $\mathrm{w}$ serii kontrolnej (na poziomie $7,8 \mathrm{MPa}$ ). W przypadku temperatury prażenia $770^{\circ} \mathrm{C}$ odnotowano niewielki (ok. 3\%) przyrost wytrzymałości względem serii kontrolnej.

Analizując zebrane dane, stwierdzono, że wraz ze wzrostem temperatury prażenia zaprawy recyklingowej wytrzymałość na zginanie kompozytu cementowego generalnie wzrastała. $Z$ rysunku 3 także można odczytać, że najkorzystniejsze wyniki uzyskano podczas prażenia gruzu (zaprawy recyklingowej) w temperaturze $770^{\circ} \mathrm{C}$. Wydłużanie czasu prażenia w przypadku niższej temperatury $\left(430^{\circ} \mathrm{C}, 550^{\circ} \mathrm{C}\right)$ nieznacznie przyczyniało się do wzrostu wartości analizowanego parametru.

\section{PODSUMOWANIE I WNIOSKI}

W procesie recyklingu konstrukcji betonowych uzyskuje się zwykle grube frakcje kruszywa większe od $4 \mathrm{~mm}$, stosowane np. jako częściowy zamiennik kruszywa naturalnego w betonach, oraz frakcje drobne do $4 \mathrm{~mm}$ traktowane jako materiał odpadowy m.in. ze względu na ich dużą nasiąkliwość.

W pracy podjęto próbę sprawdzenia możliwości zagospodarowania tego odpadu jako częściowego zamiennika cementu w kompozytach cementowych. Wykonano 11 serii beleczek zapraw normowych (w tym seria kontrolna) zawierających zaprawę recyklingową w charakterze zamiennika cementu. Zaprawa recy-

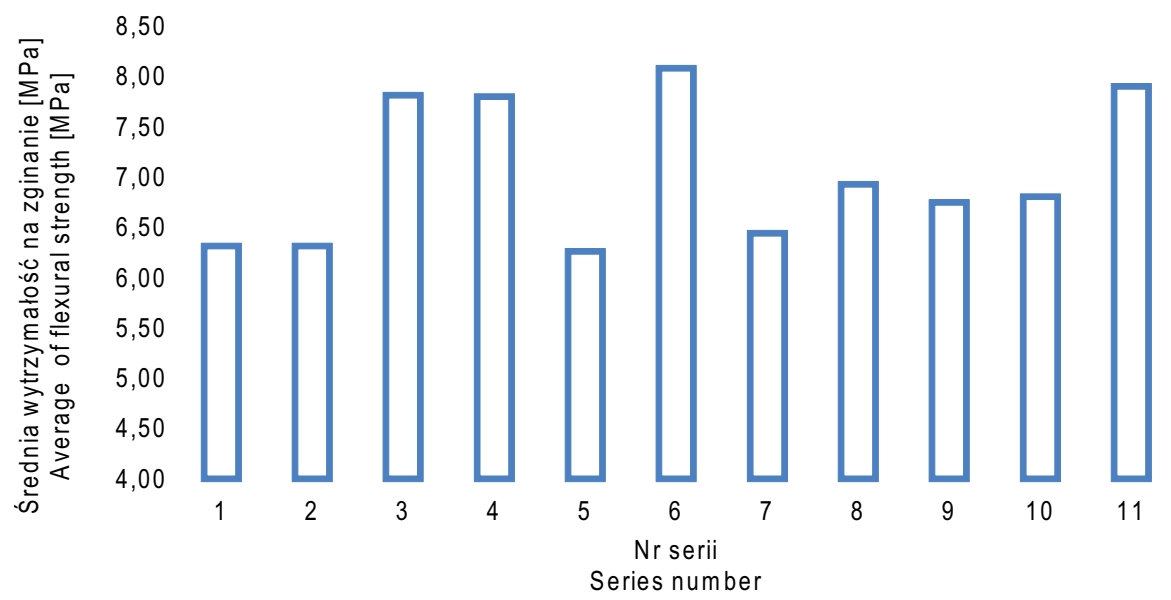

Rys. 3. Zestawienie wyników średniej wytrzymałości na zginanie kompozytów cementowych z dodatkiem zaprawy recyklingowej

Fig. 3. Comparison of the results of medium flexural strength of cementitious composites with the addition of a recyclable mortar 
Kalinowska-Wichrowska, K. (2019). Kompozyty cementowe modyfikowane aktywowanym termicznie dodatkiem recyklingowym. Acta Sci. Pol. Architectura 18 (1), 39-45, DOI: 10.22630/ASPA.2019.18.1.5

klingowa została uzyskana podczas procesu obróbki termiczno-mechanicznej gruzu betonowego, którego parametry stały się czynnikami zmiennymi w zaplanowanym eksperymencie (czas i temperatura prażenia). Otrzymane wyniki badań wskazują, że odpowiednio dobrane parametry obróbki zaprawy recyklingowej przekładają się na uzyskiwane dobre wyniki wytrzymałościowe przy jednoczesnym, słabym wpływie na nasiąkliwość kompozytów. Wprowadzenie obróbki termicznej korzystnie wpływa na badane właściwości pucolanowe materiału recyklingowego. Prawdopodobnie zapewnienie odpowiednio wysokiej temperatury prażenia tego odpadu umożliwia częściowe odwrócenie procesów hydratacji, wzbudzając utajone właściwości wiążące materiału. Dostarczenie zbyt wysokiej temperatury, w której prażony jest gruz betonowy, pogarsza właściwości takiego dodatku jako pucolany typu II. Prawdopodobnie wynika to z rozpadu węglanu wapnia na tlenek wapnia i dwutlenek węgla w wyższej temperaturze. Ogólna analiza wyników badań pozwoliła na stwierdzenie, iż najkorzystniejsze parametry analizowanych właściwości, tj. wytrzymałości na ściskanie i zginanie oraz nasiąkliwość, uzyskano podczas prażenia gruzu $\mathrm{w}$ temperaturze około $650^{\circ} \mathrm{C}$ i czasie prażenia nie dłuższym niż $60 \mathrm{~min}$. Otrzymane wyniki dowodza, iż jest możliwe zagospodarowanie tej masy odpadów do produkcji nowych kompozytów cementowych, lecz konieczne sa dalsze badania nad wyjaśnieniem procesów zachodzących podczas prowadzonej obróbki termicznej. W przyszłości planuje się wykonanie analiz pozwalających na ocenę ekonomiczną zaproponowanego rozwiązania.

\section{PIŚMIENNICTWO}

Abbas, A., Fathifazl, G., Burkan Isgor, O., Razaqpur, A. G., Fournier, B. i Foo, S. (2008). Proposed method for determining the residual mortar content of recycled concrete aggregates. Journal of ASTM International, 5 (1), 1-12. doi: 10.1520/JAI101087

Bordy, A., Younsi, A., Aggoun, S. i Fiorio, B. (2017). Cement substitution by a recycled cement paste fine: Role of the residual anhydrous clinker. Construction and Building Materials, 132, 1-8. doi: 10.1016/j.conbuildm at.2016.11.080
Chai, L., Monismith, C. L. i Harvey, J. (2009). Re-Cementation of Crushed Material in Pavement Bases (Technical Memorandum UCPRC-TM-2009-04). Institute of Transportation Studies, University of California, Davis. Pobrano z lokalizacji: http://www.ucprc.ucdavis.edu/ PDF/UCPRC-TM-2009-04.pdf.

Il'ina, L.V. i Mukhina, I. N. (2016). Estimation of the Applicability for the Filler Produced by Recycling of Concrete and Reinforced Concrete Used in Heavy Concrete. Procedia Engineering, 150, 1525-1530. doi: 10.1016/ j.proeng.2016.07.102

Lotfi, S., Eggimann, M., Wagner, E., Mróz, R. i Deja, J. (2015). Performance of recycled aggregate concrete based on a new concrete recycling technology. Construction and Building Materials, 95, 243-225. doi: 10.1016/j.conbuildmat.2015.07.021

Nam, B. H., An, J. i Youn, H. (2016). Accelerated calcite precipitation (ACP) method for recycled concrete aggregate (RCA). Construction and Building Materials, 125, 749-756. doi: 10.1016/j.conbuildmat.2016.08.048

Paige-Green, P. (2010). Preliminary evaluation of the reuse of cementitious materials. W Proceedings of 29th Annual Southern African Transport Conference (strony 520-529). Pretoria, South Africa. Pobrano z lokalizacji: https://repository.up.ac.za/bitstream/handle/2263/14877/PaigeGreen_Preliminary\%282010\%29. pdf? sequence $=1 \&$ is Allowed $=\mathrm{y}$.

PN-EN 1015-3:2000/A1:2005. Metody badań zapraw do murów. Określenie konsystencji świeżej zaprawy (za pomocą stolika rozpływu).

PN-EN 196-1:2006. Metody badania cementu. Część 1: Oznaczanie wytrzymałości.

PN-EN 197-1:2012. Cement. Część 1: Skład, wymagania i kryteria zgodności dotyczące cementów powszechnego użytku.

PN-EN 450-1:2012. Popiół lotny do betonu. Część 1: Definicje, specyfikacje i kryteria zgodności.

Politechnika Białostocka (2018). PAT.229887. Warszawa: Urząd Patentowy Rzeczypospolitej Polskiej.

Poon, C. S., Qiao, X. i Chan, D. (2006). The cause and influence of self-cementing properties of fine recycled concrete aggregates on the properties of unbound subbase. Waste Management, 26, 1166-1172. doi: 10.1016/ j.wasman.2005.12.013

Shui, Z., Xuan, D., Wan, H. i Cao, B. (2008). Rehydration reactivity of recycled mortar from waste experienced to thermal treatment. Construction and Building Materials, 22 (8), 1723-1729. doi: 10.1016/j.conbuildmat.20 07.05 .012 


\title{
CEMENT COMPOSITES MODIFIED WITH A THERMALLY ACTIVATED RECYCLED ADDITION
}

\begin{abstract}
The article presents the results of the research on cementitious composites, the composition of which was modified by a recycled additive, created (next to recycling aggregates) as a result of a specially selected concrete recycling process according to Polish patent PAT.229887 (2018). The use of a specially prepared recycling mortar as a type II additive or only a filler in cement composites, is the right way to develop this material and a strong stress towards sustainable construction. Properly selected parameters of the thermo-mechanical treatment process enable activation of pozzolana properties of this material. The proposed recycling method is an example of a comprehensive solution to the problem of complete conversion of concrete debris into valuable secondary products and their re-integration into the construction production process.
\end{abstract}

Key words: recycling mortar, concrete recycling, sustainable development, waste management 
